\title{
Foreword to the Special Section on Man-Nature Relationship
}

The relationship between the modern man and wildlife is as old as the modern human race. Typically, it is steeped in the positives and negatives. The negatives by far tend to outweigh nature's munificent largesse to muddy our perception of the ancient kinship between man and fellow creatures notwithstanding the priceless and free ecological services we enjoy. Not surprisingly though after Darwin's Origin of Species alongside the serious attempts at taming the wilderness, the immensity of the contours of positives in the relationship are taking shape with clarity. The spurt of progress in science during the post 1980s in particular is seeking to turn the tide in favour of wilderness and wildlife led by the inclusive concept of biological diversity and its role in support of the future and the quality of human life. The Ecological Society since its inception has espoused and professed that emerging interest.

In this issue of the Journal there are three papers that address some of the important aspects of these relationships. The subjects and the ecosystems addressed vary widely from those addressing challenges of farming in the neighbourhood of ecologically rich forests, to probing the quality of fresh water ecosystems for the benefit of people and then on to centers of urbanization and need for making amends for its fallout on wild creatures. The common feature across these papers however is the hope, determination and ways of overcoming the predicaments by employing technology, experiments and adaptations.

The research relating to freshwater streams in Meghalaya has sought to establish the role of biomonitoring - employing presence/absence of some of the native macroinvertebrates alongside abiotic parameters to adjudge water quality and assess watershed conditions. Using such tools and perspectives can develop the collective mindset through capacity building. Fresh water constitutes our lifeline and water quality is critical for human health. It supports significant economy via the freshwater fisheries in
India with an annual catch of 6.57 million tonnes during 2014-15.

Crop raiding by wild herbivores is a refrain in the proximity of one of the finest tiger reserves in the country - the Tadoba-Andahri located in Chandrapur district. The study centered on this ecosystem seeks to mitigate the problem. It explores the economics and the advantages of raising some of the non-palatable medicinal plants in trade that are of little interest to wild animals as opposed to crops that are routinely raided. A four phased participatory model includes an easy to follow process ranging from the selection of species to establishing market linkages for sale of value added produce. What is more, the process is recorded in the local language, Marathi in a booklet that farmers can use.

The third paper describes with examples the reality of rapid urbanization causing unrecognizable changes in habitats of species that are otherwise adapted to human presence. Infrastructure designs that facilitate various segments of development and large scale introduction of exotic plants have had varied impacts depending on the sensitivities of different native species. While the paper narrates such conflicts by their categories, it explains the processes for mitigation involving skills of informed stakeholders, the importance of awareness generation, it stresses on the need for planting and care of native tree species, use of adaptive engineering and much more. Enlightened approach has an important place in developing urban centers that care for shared spaces with wildlife. It would be amply clear that wildlife conservation and conflict resolution is not applicable just to India's wilderness and the abutting rural ecosystems. The urban centers also need to share that responsibility in our own interest and to honour our Constitution in letter and spirit.

Vishwas Sawarkar woodow1464@yahoo.co.in 